\section{Senile Plaques}

JoAnn Tschanz

Department of Psychology, Utah State University, Logan, UT, USA

Center for Epidemiologic Studies, Utah State

University, Logan, UT, USA

\section{Synonyms}

Amyloid plaques; Neuritic plaques; Senile amyloid plaques

\section{Definition}

One of the neuropathological hallmarks of Alzheimer's disease (AD) are found in the extracellular space between neurons in the brain. Fully formed senile plaques are characterized by a central beta-amyloid core and surrounded by elements of degenerating neurons (dystrophic neurites). Diffuse plaques, by contrast, are widely distributed in the brain but lack the surrounding neurites. Senile plaque counts, along with neurobrillary tangles, form the basis on which a pathological diagnosis of AD is made. Senile plaques also occur in the brains of elderly individuals without dementia but are generally of insufficient quantity to meet criteria for a pathological diagnosis of AD (Grabowski and Damasio 2004; Morris and Nagy 2004).

\section{See Also}

- Alzheimer's Dementia

- Amyloid Plaques

- Neurofibrillary Tangles

- Senile Dementia

\section{Further Reading}

Grabowski, T. J., \& Damasio, A. R. (2004). Definition, clinical features and neuroanatomical basis of dementia. In M. M. Esiri, V. M.-Y. Lee, \& J. Q. Trojanowski (Eds.), The neuropathology of dementia (2nd ed., pp. 1-33). Cambridge: Cambridge University Press.

Morris, J. H., \& Nagy, Z. (2004). Alzheimer's disease. In M. M. Esiri, V. M.-Y. Lee, \& J. Q. Trojanowski (Eds.), The neuropathology of dementia (2nd ed., pp. 161-206). Cambridge: Cambridge University Press. 